\title{
Adaptive Smoothness Constraint Image Multilevel Fuzzy Enhancement Algorithm
}

(Algoritma Peningkatan Kabur Imej Berbilang Paras Kelancaran Kekangan Mudah Suai)

\author{
Xi CHU, ZHIXIANG ZHOU*, CHAOSHAN YANG \& XiAOJU XIANG
}

\section{ABSTRACT}

For the problems of poor enhancement effect and long time consuming of the traditional algorithm, an adaptive smoothness constraint image multilevel fuzzy enhancement algorithm based on secondary color-to-grayscale conversion is proposed. By using fuzzy set theory and generalized fuzzy set theory, a new linear generalized fuzzy operator transformation is carried out to obtain a new linear generalized fuzzy operator. By using linear generalized membership transformation and inverse transformation, secondary color-to-grayscale conversion of adaptive smoothness constraint image is performed. Combined with generalized fuzzy operator, the region contrast fuzzy enhancement of adaptive smoothness constraint image is realized, and image multilevel fuzzy enhancement is realized. Experimental results show that the fuzzy degree of the image is reduced by the improved algorithm, and the clarity of the adaptive smoothness constraint image is improved effectively. The time consuming is short, and it has some advantages.

Keywords: Adaptive; fuzzy enhancement; image; multilevel; smoothness constraint

\section{ABSTRAK}

Disebabkan masalah kesan peningkatan yang lemah dan masa yang panjang oleh algoritma tradisi, satu cadangan algoritma peningkatan kabur imej berbilang paras kelancaran kekangan mudah suai berdasarkan penukaran sekunder warna kepada skala kelabu dicadangkan. Dengan menggunakan teori set kabur dan teori set kabur teritlak, transformasi pengendali kabur yang baru telah dijalankan untuk mendapatkan operator kabur linear yang baru. Dengan menggunakan transformasi keahlian linear teritlak dan transformasi songsang, penukaran sekunder warna kepada skala kelabu bagi imej kekangan mudah suai dijalankan. Digabungkan dengan operator kabur teritlak, rantau kontras peningkatan kabur imej kekangan mudah suai direalisasikan dan peningkatan imej dalam berbilang paras direalisasikan. Hasil uji kaji menunjukkan bahawa imej tahap kabur dikurangkan oleh algoritma yang lebih baik dan kejelasan imej kelancaran kekangan mudah suai diperbaiki dengan berkesan. Masa yang diperlukan singkat dan ia mempunyai beberapa kelebihan.

Kata kunci: Imej; berbilang paras; kekangan yang tidak rata; peningkatan kabur; penyesuaian

\section{INTRODUCTION}

Image enhancement and image segmentation technology are used in adaptive smoothness constraint image multilevel fuzzy enhancement algorithm. Image enhancement is used to improve the visual effect of image, or to transform the image into a form suitable for human eyes and machine analysis. Image segmentation can extract the target of interest and remove the background of non-interest. Most of the energy functions of interest are non-convex and have multiple minimum values, resulting in most methods finding only approximate solutions (Ramos Gandolfi et al. 2018; Sanchez Camacho \& Martinez Morales 2017; Wang et al. 2018; Zhou et al. 2017). Therefore, the minimization process is often difficult. The enhancement is only to emphasize or sharpen the edge, contour, contrast and other features of the image, increase the dynamic range of the selected features, make the feature detection or recognition easier, without increasing the related information of the image. Image segmentation can test the effect of image pre-processing and obtain interested targets after segmentation. However, there is no image segmentation algorithm that can be applied to all fields at present (Liu 2017). The existing image segmentation methods are divided into the following categories: Threshold segmentation, edge detection, division segmentation, and watershed transform. Traditional image enhancement methods for specific problem have great limitations. Because of the uncertainty and fuzziness of the image itself, the method of image enhancement based on fuzzy set theory becomes possible (Liu et al. 2017).

The two technologies have a long history of development (Ju et al. 2016). In 1965, Zadeh proposed the fuzzy set theory. In 1979, Japanese scholar Otsu proposed a more classical threshold Otsu method, also known as the maximum between-class variance threshold segmentation algorithm, which can adaptively determine the threshold (He \& Dong 2018; Liu 2018; Prabha \& Kumar 2017; Zong et al. 2018). In 1981, Pal and King proposed an image fuzzy enhancement algorithm to enhance image processing in fuzzy space. In 2004, Lin and Chen proposed the generalized fuzzy 
set theory, and using GFS theory, proposed an image edge detection algorithm, which is generalized fuzzy operator method. For the shortcoming of the traditional fuzzy enhancement algorithm, a new linear generalized fuzzy operator is constructed based on the theory of GFS and GFO in this paper. Then, an adaptive multilevel image bilinear generalized fuzzy enhancement algorithm is proposed. In 2007, Shi proposed a fuzzy membership function optimization method based on particle swarm optimization. Lu et al. (2017) also proposed an adaptive fuzzy enhancement algorithm based on particle swarm optimization. However, most of these algorithms belong to the single level fuzzy enhancement algorithm. In order to overcome the shortcomings of the traditional single level fuzzy enhancement algorithm, a new fuzzy enhancement algorithm is proposed in this paper ( $\mathrm{Li}$ et al. 2017).

\section{RESEARCH STATUS OF IMAGE MULTILEVEL FUZZY ENHANCEMENT ALGORITHM}

Traditional enhancement methods can be divided into two categories: Frequency domain method and space domain method. The former is to filter in the transform domain of the image, and finally inversely transforms the filtered image to the spatial domain in order to achieve the purpose of enhancement. The latter is based on the gray level mapping transformation, which directly processes pixels in the image.

The traditional enhancement methods, either in the spatial domain or in frequency domain, are mostly global enhancement methods. Global spatial domain enhancement methods, such as the most widely used contrast stretching and histogram equalization, are simple in concept, easy to handle in mathematics and program. So good image enhancement effect is achieved in some low requirements. However, pixels with different grayscale in different positions often show different image structures. If the global grayscale changes are adopted, it is to fail to achieve the desired results. In addition, there is still unexpected noise enhancement effect for global histogram equalization. For this problem, many scholars have proposed some new methods of image local enhancement, such as adaptive histogram equalization, adaptive contrast enhancement, an adaptive neighborhood extension contrast enhancement algorithm, conformal contrast enhancement method, and local histogram equalization with constraint condition (Huang et al. 2016). This kind of enhancement algorithms can use the corresponding histogram equalization method for image processing according to the gray distribution characteristic of the pixel neighborhood of the image, and the enhancement effect is better. But the computation is heavy, and improper processing will introduce unexpected noise interference.

To sum up, in the enhancement algorithm, how to effectively remove the noise and effectively utilize the neighborhood information around the pixel and improve the computing speed is the difficult problem in the research.
In addition, how to use human visual characteristics to suppress noise and improve the visual effect of the enhanced image needs further exploration (He et al. 2017). Because of the fuzziness between the neighborhoods of the image, the expression form of human visual characteristics also has fuzziness, therefore, the fuzzy technology should be an effective tool for the research.

In recent years, fuzzy set theory has been widely applied in pattern recognition and computer vision. In the image processing method based on fuzzy theory, human guidance can be introduced (heuristic rules expressed in linguistic terms). This guidance is highly nonlinear and difficult to express by traditional mathematical models. More importantly, this method allows us to integrate heuristic rules with traditional methods. The parameters of the adaptive rule are easy to expand, so that the filter can be designed very flexibly. For example, the fuzzy rule is used to improve the selection of filter window scale in traditional median filter, and improves the Gaussian noise reduction performance. The adaptive fuzzy filtering operator can protect image details and filter Gaussian noise better. The size of the window in the algorithm is determined by the degree of neighborhood consistency and the degree of neighborhood consistency is also derived from a fuzzy logic rule. The disadvantage of the algorithm is that the filtering effect of impulse noise is poor.

\section{NEW LINEAR GENERALIZED FUZZY OPERATOR TRANSFORMATION OF IMAGE}

The proposed new fuzzy enhanced image linear generalized fuzzy operator includes the three aspects of the applied technology, the improved algorithm and the image color enhancement. Through systematic analysis and experiments, it is proved that the advantages of the proposed algorithm are better than the previous methods. The basic principle of image segmentation based on fuzzy enhancement is described as follows. First, image segmentation is considered as minimization of energy function (Huang et al. 2018). The optimal image segmentation is realized when the energy function is minimum. Then, a graph is defined for a given energy function, so that the cost of the cut set of the graph is exactly equal to the given energy function. Finally, by minimizing the minimum cut of a graph, the given energy function is minimized and the optimal image segmentation is achieved (Yi et al. 2016).

The main methods are Ostu method and maximum entropy method.

Assume $\{0,1,2, \ldots, \mathrm{L}-1\}$ represents $\mathrm{L}$ grayscales of a $\mathrm{M} * \mathrm{~N}$ image, $\mathrm{n}(\mathrm{i}=0,1,2, \ldots, \mathrm{L}-1)$ is the number of the pixels with the grayscale $i$. The total number of the pixels of the image is MN $\left(n_{0}+n_{1}+n_{2}+\ldots+n_{L-1}\right)$. Therefore, the probability of the grayscale $i$ is $p_{i}=n_{i} / M N$. Then $\sum_{\mathrm{i}=1}^{t} P_{i}=1, \mathrm{P}_{\mathrm{i}} \geq 0$. Assume there is a threshold $\mathrm{T}(0<\mathrm{T}<\mathrm{L}-1)$. The pixels of the input image are divided into two classes: $\mathrm{C} 1$ and $\mathrm{C} 2 . \mathrm{C} 1$ is all pixels with the grayscale of $[0, \mathrm{~T}]$, 
$\mathrm{C} 2$ is the pixels with the grayscale of $[\mathrm{T}+1, \mathrm{~L}-1]$. So the probability of assigning the pixels to the $\mathrm{C} 1$ class is $\mathrm{P} 1$ (T), given by

$$
\mathrm{P}_{1}(\mathrm{~T})=\sum_{\mathrm{i}=1}^{t} P_{i}
$$

The probability of assigning the pixels to the $\mathrm{C} 2$ class is P2 (T). The average grayscale of pixels assigned to the $\mathrm{C} 1$ class is $\mathrm{m} 1 \sum_{i=0}^{L-1} i p i$.

By using the definition of between-class variance, it can be derived that

$$
\alpha^{2}{ }_{B}=P_{1} P_{2}\left(m_{1}-m_{2}\right)^{2}
$$

The maximum value T obtained with (2) is the best threshold for the algorithm. In conclusion, first, whether it is the edge point of the image is judged, and then the pixels of the non-edge points are removed, processed with the histogram statistics, and finally the threshold grayscales at all levels are obtained (Wang et al. 2017). Secondly, the maximum entropy method can be divided into one-dimensional maximum entropy method and twodimensional maximum entropy method. One-dimensional maximum entropy method is based on the entropy of the histogram of the image, and the segmentation threshold is obtained adaptively. But the one-dimensional maximum entropy method is vulnerable to noise interference, and cannot reflect the local spatial information of the image (Bao 2017). Two-dimensional maximum entropy method was first proposed by Abutaleb (1989). He extended the one-dimensional histogram to the gray level and the neighborhood average grayscale two-dimensional histogram is obtained. Considering the neighborhood average grayscale, the segmentation result of the twodimensional maximum entropy method is obviously improved compared with the one dimensional maximum entropy method. The selection steps are as follows. First the $R(i, j)$ values of all pixels in the image are calculated to form an image edge feature matrix $R=\{R(i, j), 1 \leq i \leq M$, $1 \leq j \leq N\}$. A threshold $T$ is set. When $R(i, j) \geq T$, the pixel is the edge point of the image, otherwise it is a non-edge point. The pixels of non-edge points are removed. Secondly, histogram statistics of pixel grayscale at the edge of image is carried out. Finally, the maximum value of the local envelope of the image is calculated as the threshold grayscale of all levels in the fuzzy enhancement algorithm (Wang \& Zheng 2016).

\section{COLOR-TO-GRAYSCALE CONVERSION OF GENERALIZED FUZZY SPACE}

There are many traditional single level fuzzy enhancement algorithms, and the most typical one is fuzzy enhancement algorithm proposed by Pal et al. (1981). The steps of the algorithm include:
$\mathrm{M} \times \mathrm{N}$ dimension image $\mathrm{X}$ with $\mathrm{L}$ grayscales is regarded as a fuzzy dot matrix; Fuzzy enhancement of image; and transform the enhanced fuzzy features.

The algorithm makes a part of the edge near the threshold parameter enhanced, but at the same time, the other edges far away from the threshold parameters are suppressed, resulting in a decline in the visual effect of the image (He et al. 2016). Other traditional single level fuzzy enhancement algorithms also have similar defects in edge extraction and visual effects.

In order to effectively solve the shortcomings of the traditional single level fuzzy enhancement algorithm, improving the multi-level image fuzzy enhancement has become a top priority for many researchers. Images with more visual perception information and high dynamic range images with higher image detail quality have brought more research interest. Therefore, the following improvements are proposed (Yue et al. 2016).

The key of image multilevel fuzzy enhancement algorithm is the selection of grayscale in all levels of image. If the selection is reasonable, the edge information of different grayscales in the image can be taken into account, so that each edge of the image is enhanced at the same time, and the level of the image is more distinct after the enhancement (Song et al. 2017). If the selection is improper, some edges may be enhanced, while other edges cannot be enhanced or even suppressed (Wang 2017). The result of linear fuzzy enhancement can sharpen the edge of threshold grayscale at all levels. In this paper, through the introduction of fuzzy entropy, the different levels and threshold parameters are well selected (Shakeri et al. 2017). The specific process is as follows.

Firstly, the fuzzy entropy of the image is defined. The pixel graysacle of a $\mathrm{M} \times \mathrm{N}$ dimensional image $\mathrm{X}$ with $\mathrm{L}$ graysacles is normalized to the $[0,1]$ interval. Based on the graysacle of the image, a fuzzy set is defined and its membership degree is

$$
\mu_{\mathrm{m}}(\mathrm{x}(\mathrm{i}, \mathrm{j}))=1 /[1+|\mathrm{x}(\mathrm{i}, \mathrm{j})-\mathrm{m}|]
$$

This equation represents the degree of membership of the pixel in the image and its area (the normalized value of $\mathrm{M}$ is the grayscale of the pixel after normalization). If the difference of feature value between a pixel and its own region is smaller, the membership of the pixel is larger; conversely, the membership of the pixel is smaller (Sun et al. 2017). $(0.5 \leq \mu \mathrm{m}(\mathrm{x}(\mathrm{i}, \mathrm{j}) \leq 1)$. According to information theory, fuzzy entropy can be defined on the above fuzzy set.

$$
\mathrm{H}_{\mathrm{m}} \mu_{\mathrm{m}}(\mathrm{x}, \mathrm{i}, \mathrm{j})=-\left(\mu_{\mathrm{m}}(\mathrm{x}(\mathrm{i}, \mathrm{j}))\right) \times 1 \mathrm{~g}\left[\mu_{\mathrm{m}}(\mathrm{x}, \mathrm{i}, \mathrm{j})\right]
$$

When the grayscale $x(i, j)=m$, fuzzy entropy is minimum, the entropy of fuzzy entropy near $x(i, j)=m$ has symmetry. In the gray value matrix of the image, a window with the center of $(i, j)$, and the size of $n \times n(n$ is odd) is taken. A measure based on fuzzy entropy is defined on this window (Li et al. 2018). Finally, multilevel 
threshold parameters are determined. A threshold in the matrix is taken to determine whether it is an edge point. Histogram is used to process the pixel grayscale at the edge of the image. The image can be subdivided into many subimages. It can be segmented with different threshold. The pixel threshold is determined by the pixel position in the subimage, therefore, this class of threshold is called the binaryzation of the adaptive local critical value, and the critical value of the pixel is determined by the grayscale and the local grayscale. How to estimate the threshold of subimages obtained by subdivision of images is the key point in the application of this method. This method is suitable for identifying images with heavy interference or poor quality, and has a wider range of applications, but there are also problems of slow speed and artifact. Grayscale schematic of different field of view pixels is shown in Figure 1.

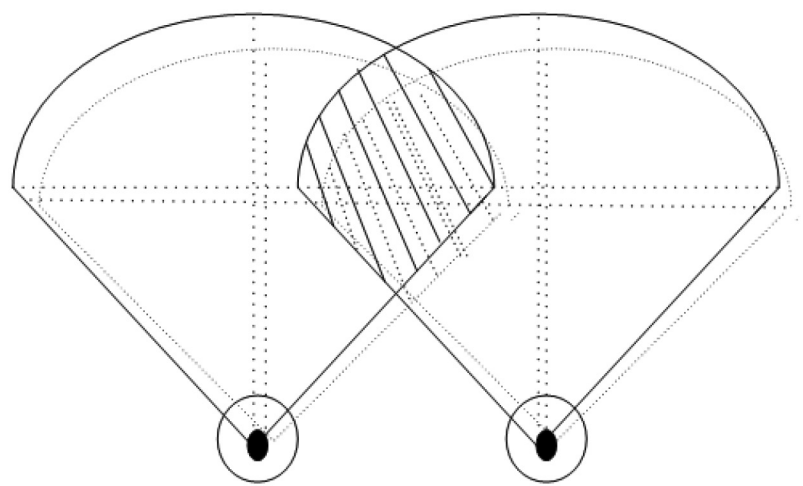

FIGURE 1. Grayscale schematic of different field of view pixels

The form of fuzzy membership function is expressed as

$$
\mu_{\mathrm{ij}}=\mathrm{G}\left(\mathrm{x}_{\mathrm{ij}}\right)=\mathrm{x}_{\mathrm{ij}} /(\mathrm{L}-1)
$$

where L- 1 is the maximum grayscale of the image $\mathrm{X}$, $\mathrm{i}=1,2, \ldots, \mathrm{M}, \mathrm{j}=1,2, \ldots, \mathrm{N}$, xij is the grayscale of the (i, j) pixel. The value of this membership function is in the $[0,1]$ interval. Fuzzy enhancement does not cause much of the low grayscales of the original image to be set to 0 , which saves the low grayscale edge information (Quan et al. 2016). The calculation process is simplified and the amount of calculation is reduced. The transformation of the final fuzzy set to the image set is carried out ( $\mathrm{Li} \&$ Qiao 2017).

\section{IMPROVED MULTILEVEL IMAGE FUZZY ENHANCEMENT METHOD}

Using different membership functions has little effect on the final contour extraction (Cai et al. 2016). In order to simplify the calculation process and improve the speed of the algorithm, the generalized linear operation is adopted in this paper. Zhang et al. (2017) proposed that there is no need to follow the inherent addition and subtraction operations in the actual image processing. Some nonlinear operations can be designed according to the noise level of the actual image and some characteristics of the mask itself. In the design of homomorphic filters, the image is transformed by log transformation, the image data is transformed to the logarithmic domain, and then the post-processing of the image (such as low pass filtering) is carried out. The effect of this processing is greatly improved compared with the traditional design method (Ren et al. 2017). The design idea is shown as Figure 2.

In Figure 2, $\Phi$ is a user-defined function. If $\Phi$ is defined as $Y=X$, the system is the same as the normal operation, that is, normal linear operation. In practical design, $\Phi$ is defined as a nonlinear function. Therefore, it can be called a generalized linear operation. A large application is divided into several small tasks. Only by cooperation between tasks, a large project can be completed. In order to successfully accomplish mission tasks, sometimes there is a need to share some resources with no conflict, and sometimes there is a need to establish a restrictive relationship between them. Therefore, a perfect multitask operating system must establish a perfect synchronization and communication mechanism. Synchronization between tasks is triggered by certain conditions. The result of synchronization is that tasks are executed in a predetermined order. The MIN operator is used to extract the edge of the image (Li \& Liu 2016).

The edge matrix of the image is defined as

$$
\mathrm{E}=\left[\mathrm{e}_{\text {min }}\right]_{\mathrm{M} \times \mathrm{N}}+\mathrm{e}_{\text {min }}=\mathrm{x}_{\min }-\min \left\{\mathrm{x}_{\mathrm{ij}}\right\},(i, j) \in \mathrm{S}
$$

where $S$ is the $3 \times 3$ window with the center of $(m, n)$, $x$ min is the grayscale of the pixel $(\mathrm{m}, \mathrm{n})$.

Traditional color image enhancement methods usually have many problems, such as unnatural harmonization of color, overstretching of contrast, excessive enhancement and blurring of details and halo. The proposed color image enhancement algorithm is designed to adjust the image contrast reasonably by using the nonlinear tonal mapping

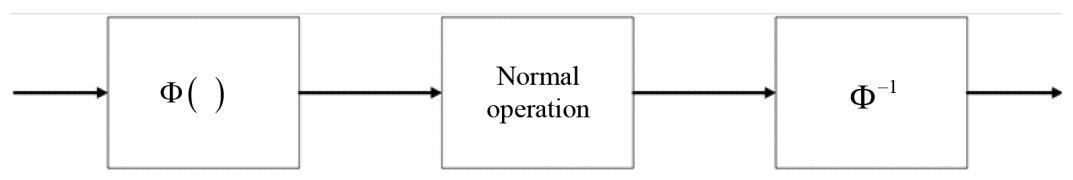

FIGURE 2. Block diagram of generalized linear operation 
operator, and combined with the corresponding human visual perception model and theory method to make the enhanced target image overcome the defects in the current color enhancement algorithm, and obtain a color enhancement image with high quality and color perception consistency (Kong et al. 2019).

In recent years, the model based on human visual perception system and corresponding tone mapping operators have developed rapidly. A typical method is the enhancement method based on Retinex theory proposed by Land in 1964. The basic theory of this method simulates the computational model of the illumination and color perception of the human visual system. Meylan and Susstrunk (2006) proposed the corresponding Retinex theory tone mapping algorithm based on single scale is proposed to compress the dynamic range of high dynamic range image, which makes the result image conforms to the visual perception of human eyes. Jobson et al. (1997) proposed a dynamic range compression method based on multiscale Retinex. The method reduces the halo phenomenon to some extent, but it cannot be completely removed. The image is shown in Figure 3.

Although these methods have made a great development in image enhancement, because of the existing global mapping methods, the function is simple and cannot complete the accurate or approximate simulation of human visual features and realize the brightness mapping, which causes the loss of details and the reduction of image contrast. Some local mapping methods introduce different degrees of noise, such as halo around high contrast edges. The reason is that the relative contrast between the brightness obtained by using the local mapping operator and the brightness of the original image cannot be well maintained. In short, the tone mapping method based on visual perception has the advantages of simplicity and low complexity, but it also has shortcomings. For example, most of them are directly dependent on the processing of pixel intensity information, which cannot truly reflect the information of the pixel neighborhood and the content of the image, resulting in the loss of details in the processing of high contrast or high dynamic range compression. In addition, due to the nonlinearity of the selected mapping function, the local non-monotonicity may result in the reversal of pixel value, which makes the result image unnatural.

In the image enhancement method, the gradient information of the image is used to detect the change rate of the pixel value of the image, which can be used to identify the importance information of the image. The image reconstruction is obtained by using

$$
\mathrm{I}_{\text {out }}^{\mathrm{c}}=\left(\mathrm{I}_{\text {in }}^{\mathrm{c}} / \mathrm{L}_{\text {in }}\right)^{\mathrm{s}} \times \mathrm{L}_{\text {out }}, \mathrm{c} \in\{\mathrm{R}, \mathrm{G}, \mathrm{B}\}
$$

where $\mathrm{I}^{\mathrm{c}}$ in is the pixel value of the corresponding color channel in the input original image; $\mathrm{I}_{\text {out }}^{\mathrm{c}}$ is the pixel value of the corresponding color channels in the compressed output image; $\mathrm{L}_{\text {in }}$ and $\mathrm{L}_{\text {out }}$ are the brightness values of the original input image and the output image.

The basic process is described as follows.

Color space transformation: Color space transformation is carried out for the input original image. In the proposed algorithm, the original image is transformed from the original color space to the color space of the color component.

Gradient extraction: According to the brightness components separated from the enhanced original image, the corresponding gradient information is calculated.

Gradient information enhancement. Synthesis of enhanced gradient information. Reconstruction of the enhanced image.

The spatial domain contrast enhancement method is the fastest and effective method in image enhancement processing. It mainly consists of two methods of linear and nonlinear contrast stretching processing. The former method is simple and efficient in expression and computation, but the results do not accord with human perception. The latter methods are mainly histogram equalization, Gamma correction, histogram matching,

\begin{tabular}{|c|c|c|c|c|c|c|c|c|c|c|c|c|c|}
\hline 1 & 3 & 5 & 8 & 4 & 6 & 7 & 2 & 1 & 4 & & 7 & 0 & Highest \\
\hline 8 & 7 & 8 & 9 & 7 & 5 & 5 & 1 & 2 & & & 5 & 8 & \\
\hline 5 & 5 & 4 & 6 & 8 & 7 & 6 & 8 & 4 & & & 8 & & \\
\hline 8 & 4 & 6 & 8 & 1 & 8 & 4 & 6 & 8 & & & 3 & & \\
\hline 8 & 4 & 5 & 6 & 7 & 6 & 4 & 6 & 5 & & & 13 & & \\
\hline 10 & 8 & 7 & 9 & 9 & 8 & 7 & 6 & 8 & & & 11 & & \\
\hline 15 & 10 & 9 & 8 & 9 & 10 & 8 & 11 & 10 & & & 13 & & \\
\hline 11 & 10 & 11 & 13 & 8 & 9 & 9 & 10 & 1 & & & 10 & & \\
\hline 11 & 10 & 14 & 9 & 10 & 11 & 7 & 8 & 9 & & & 8 & & Priority \\
\hline 9 & 10 & 11 & 12 & 10 & 8 & 9 & 17 & $1 c$ & 1 & & 14 & & minimum \\
\hline 12 & 10 & 9 & 8 & 9 & 11 & 10 & 8 & 10 & 1 & & 13 & 1 & \\
\hline
\end{tabular}

FIGURE 3 . Task priority variable data table 


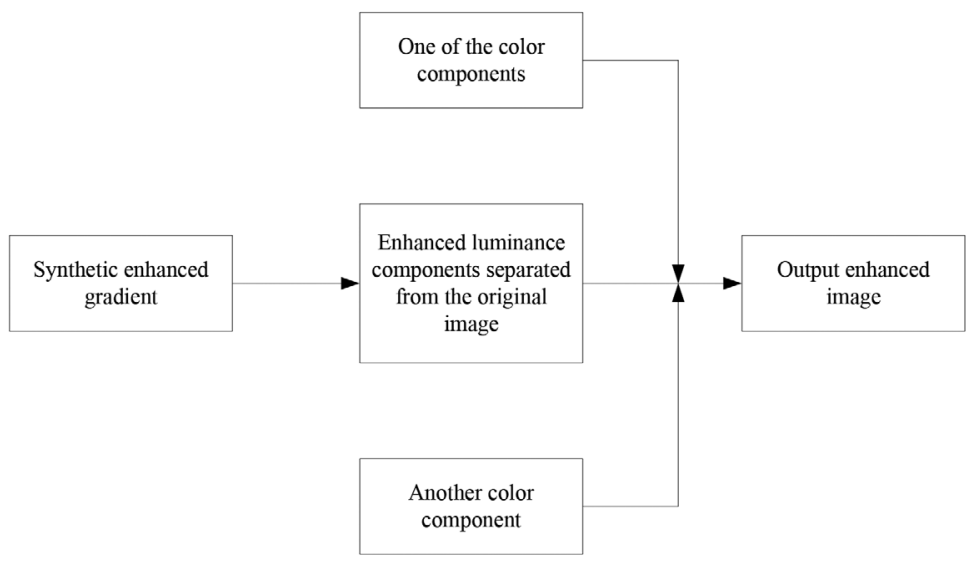

FIGURE 4. Enhanced color image reconstruction

edge sharpening, and all kinds of curve models that simulate visual perception characteristics. For color images, contrast perception, color consistency, and the complete effect of reconstructed images are all factors that must be considered in enhancement processing. For this purpose, the corresponding image models suitable for human perception are introduced into the actual enhancement process. In recent years, the Retinex model has attracted wide attention from researchers, and is also very applicable.

The basic expression of the theory is given by

$$
I(x, y)=R(x, y) \times L(x, y)
$$

where $I(x, y)$ is the input image to be enhanced, $R(x, y)$ is the reflection component, and $L(x, y)$ is the brightness component. In color image enhancement processing, first, the original RGB color image is transformed to the color space with the separation of brightness and chromaticity, and its brightness component is taken as an input image. The brightness evaluation can be completed by convolution operation, given by $L(x, y)$ * $F(x, y)$. Because of the continuous development and application of Retinex theory in image enhancement, the path-based Retinex, center surround Retinex, Retinex based on variational framework and multi-scale Retinex are derived. The improvement of color consistency and halo removal is researched.

In order to further enhance the brightness enhancement and ensure color consistency, the original image is transformed to a specific space before the optimization of the genetic algorithm, and then the gray information of the original image is decomposed. The Retinex theory is used to separate the brightness image and reflection image. The low frequency part after separation is represented by brightness map L, while the high frequency part is represented by reflection map $\mathrm{R}$. The ratio of $\mathrm{L}$ and $\mathrm{R}$ in the original image is adjusted to enhance the image quality and maintain color invariance.

\section{EXPERIMENTAL RESULTS AND ANALYSIS}

In order to verify the validity of the method, a simulation experiment is carried out. First, comparison experiment is performed on the enhanced image for scenic photos. After testing, the color and sharpness of the image will be changed obviously, which will enable the observer to feel better visually. The results are shown in Figures 5 and 6 .

In order to further verify the excellent performance of the proposed method and the value of the objective

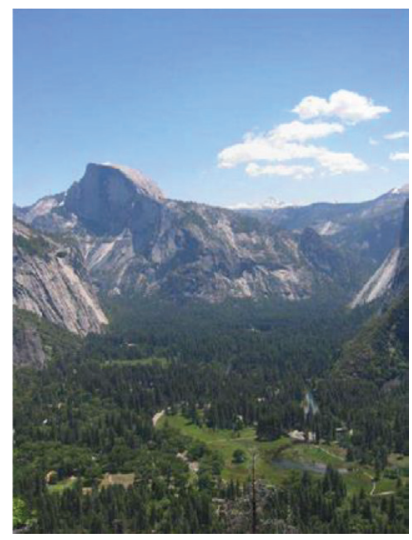

FIGURE 5. Original image

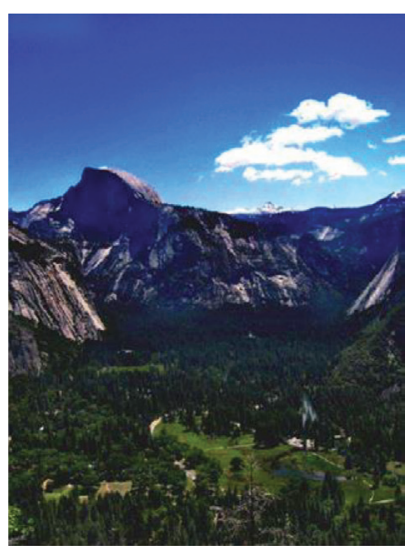

FIGURE 6. Enhanced image 
TABLE 1. Comparison of PSNR

\begin{tabular}{lcc}
\hline Image name & Image size & Algorithm in this paper \\
\hline Original image & $460 * 620$ & 36.15 \\
Enhanced image & $340 * 260$ & 34.81 \\
PSNR Original image & $470 * 620$ & 10.42 \\
PSNR Enhanced image & $340 * 280$ & 7.65 \\
\hline
\end{tabular}

contrast image, the peak signal to noise ratio, one of the most commonly used parameters of the image quality evaluation, is used for evaluation. The peak signal to noise ratio is defined as PSNR $=10 * \log 10(\mathrm{~L}-1) 2 /$ RMSE.

The experimental results show that the proposed method works well on image enhancement and produces a natural scenic image and clearer detail information content, which is more consistent with the human visual sense. Satisfactory prediction accuracy and reliability are obtained. The experimental data are shown in Figures 7 and 8.

Taking random region images as experimental reference, the improved multilevel enhancement algorithm is applied in this paper. The algorithm can automatically detect the corresponding grayscale of each edge of the image, and use it as the basis for selecting the threshold grayscale of different levels in the multilevel fuzzy enhancement algorithm. The whole algorithm does not require human intervention, and the image fuzzy enhancement process can be completed adaptively. The extracted edge information becomes more and more edge information can be described. Compared with the original image and the enhanced image, it can be seen that the difference of edge contrast in the enhanced image is obviously increased, and the important information of the image feature is more prominent. The edge contour of the enhanced image is more detailed, accurate and hierarchical, and the edge contour information of the detail is more abundant. After the image fuzzy enhancement processing, the image edge contour is more complete, the detail expression is more detailed, and the image is full of sense of hierarchy. It is conducive for the next image processing. The images before and after image enhancement are shown in Figures 9 and 10.

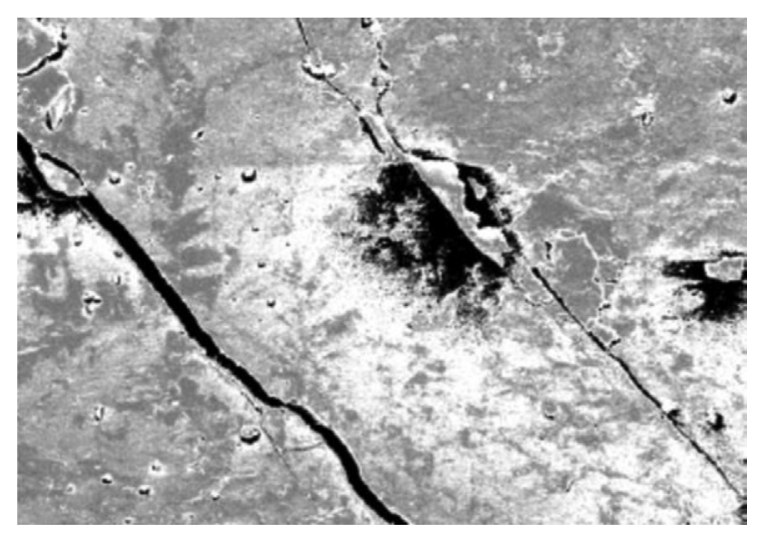

FIGURE 7. Original image

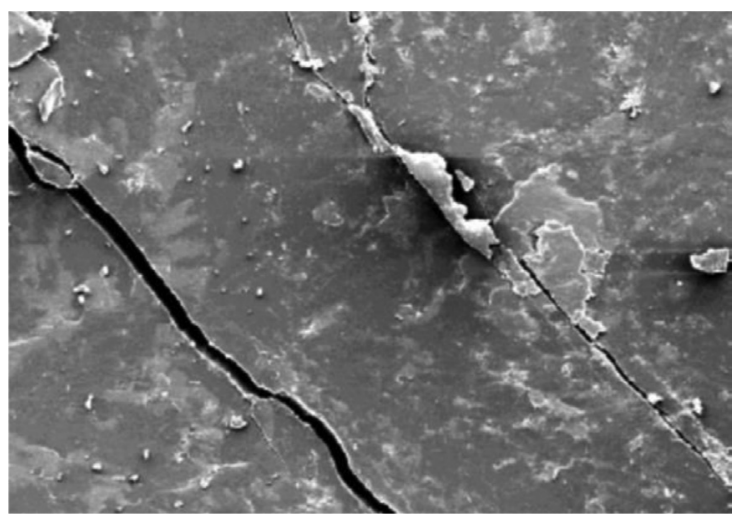

FIGURE 8. Image after multilevel fuzzy enhancement

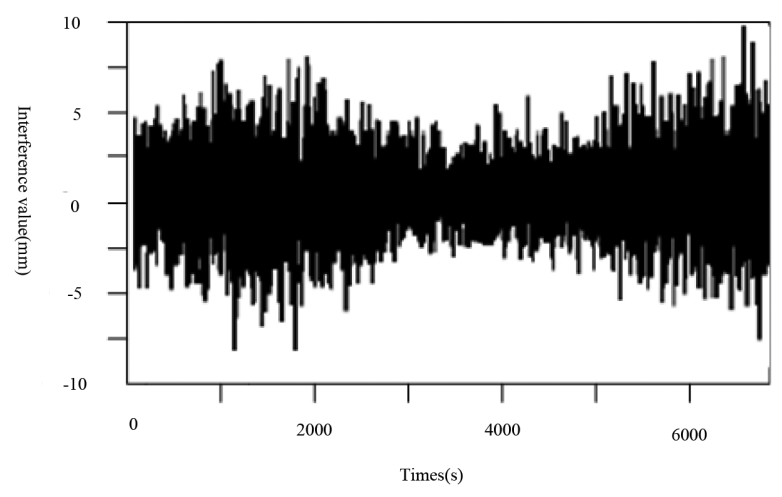

FIGURE 9. Denoising and detection result obtained with the traditional method

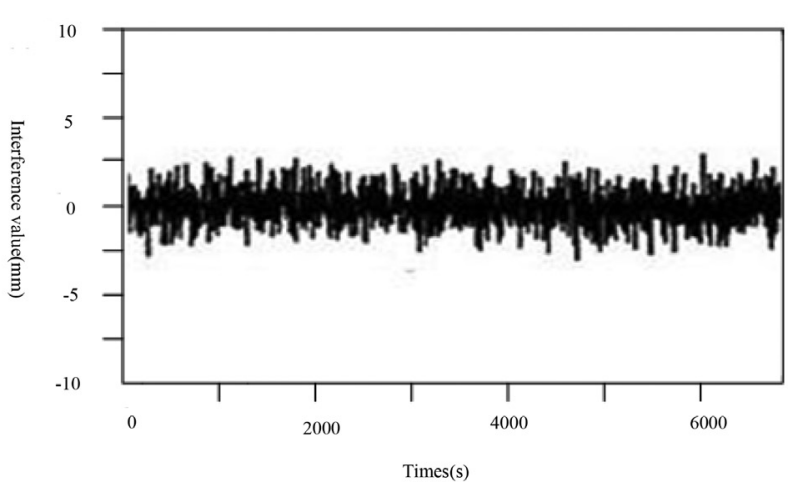

FIGURE 10. Denoising and detection result obtained with the proposed method

From Figures 7 and 8, it can be seen that, the proposed algorithm can improve the gray difference between the edge of the crack and the background and avoid the 
problem of image distortion. The comparison results show that the proposed algorithm can better extract the edge of the image and effectively suppress the noise.

From Figures 9 and 10, it can be seen that, the proposed algorithm can effectively suppress the noise during image processing and guarantee the quality of image processing. A series of experimental results show that the adaptive smoothness constraint image multilevel fuzzy enhancement algorithm can not only extract the edge more accurately than the traditional algorithm, but also solve the problem of noise reduction. After image enhancement, the color is more abundant, which can make the observer see things more directly and visually.

\section{CONCLUSION}

In the adaptive smoothing constrained image multilevel fuzzy enhancement algorithm, the generalized fuzzification of gray space and the color-to-grayscale conversion of the generalized fuzzy space are realized by using the linear generalized membership transformation and its inverse transformation. The linear generalized fuzzy enhancement processing for generalized fuzzy membership space is completed. The best quality enhancement image is obtained by adjusting parameters. Finally, the edge contour of the enhanced image is extracted by using the MIN operator. In color, in order to improve the low light image and low contrast image, and enhance its visual effect, the basic problem is proposed to be solved based on the research and analysis of relevant literature. The idea and realization process of the corresponding algorithms are deeply analyzed, and finally the experimental verification results are given. Experimental results show that the proposed algorithm is effective in image processing, and can effectively suppress noise. The enhanced image is more consistent with human visual perception. The high contrast region enhancement processing is achieved. It has good visual effect in color image enhancement. Compared with other traditional methods, the proposed algorithm has high efficiency and accuracy, and is suitable for real-time application.

\section{ACKNOWLEDGEMENTS}

National Natural Science Foundation Project - Research on the method of deducing holographic deformation and structural state of bridge based on image contour stacking analysis (No. 51778094); and National Youth Science Fund Project - Study on bridge safety state monitoring method and early warning theory based on bridge shape change (No. 51708068).

\section{REFERENCES}

Abutaleb, A.S. 1989. Automatic thresholding of gray level pictures using two-dimensional entropy. Comput. Vision Graphics Image Process 47: 22-32.

Bao, D.M. 2017. Design and application of visualization software for computer remote image definition processing. Modern Electronic Technology 40(19): 98-101.
Cai, Z.P., Niu, C., Zhang, X.Y. \& Cai, D.C. 2016. Target tracking algorithm based on fuzzy adaptive ckf. Electro-optic and Control 10: 8-12.

He, F.J., Li, Q.W., Han, H., Zhang, J.Q. \& Tan, X.J. 2017. Adaptive enhancement of borehole images based on homomorphic filtering and curve let transform. Sensors and Microsystems 36(8): 145-148.

He, R.J., Fan, Y.Y., Wang, Z.Y. \& Feng, D. 2016. A new method for single fog image restoration based on non-local total variation regularization optimization. Journal of Electronics and Information Technology 38(10): 2509-2514.

He, W. \& Dong, Y. 2018. Adaptive fuzzy neural network control for a constrained robot using impedance learning. IEEE Transactions on Neural Networks \& Learning Systems 29(4): 1174-1186.

Huang, W.G., Zhang, Y.P., Bi, W., Gao, G.Q. \& Zhu, Z.K. 2018. Low illumination image decomposition and detail enhancement under gradient sparse and least square constraints. Acta Electronica Sinica 46(2): 424-432.

Huang, S., Li, Z., Li, F. \& Huang, M.M. 2016. Fast fuzzy clustering image segmentation based on improved particle swarm optimization and adaptive filtering. Computer Measurement and Control 24(4): 171-173.

Jobson, D., Rahman, Z. \& Woodell. G. 1997. A multiscale Retinex for bridging the gap between color images and the human observation of scenes. IEEE Trans. Image Processing 6(7).

Ju, G., Yuan, L., Liu, X.Y. \& He, W. 2016. Adaptive image enhancement method based on multi-algorithm fusion. Acta Photonica Sinica 45(12): 136-144.

Kong, L.H., He, W., Yang, C.G., Li, Z.J. \& Sun, C.Y. 2019. Adaptive fuzzy control for coordinated multiple robots with constraint using impedance learning. IEEE Transactions on Cybernetics 49(8): 3052-3063.

Land, E.H. 1964. The Retinex. American Scientist 52: 247-264.

Li, L. \& Qiao, W.Z. 2017. Research on edge detection of irregular defects based on fuzzy enhancement algorithm. Sensor World 23(9): 13-16.

Li, T., He, X.H., Qing, L.B. \& Teng, Q.Z. 2017. Super Resolution reconstruction of noisy images based on adaptive block set cut a priori. Acta Automatica Sinica 43(5): 765-777.

Li, X. \& Liu, Z.Y. 2016. Research on fuzzy adaptive ant colony algorithm based on cloud model. Computer Engineering and Application 52(2): 24-27.

Li, Y.X., Zhao, M. \& Sun, D.H. 2018. A fast image enhancement algorithm for highway tunnel pedestrian detection. Conference: 2018 Chinese Control and Decision Conference (CCDC). pp. 3485-3490.

Lin, Y. \& Chen, W. 2004. An adaptive speed term based on generalized fuzzy operator for level set segmentation. 2004 2nd IEEE International Symposium on Biomedical Imaging: Nano to Macro (IEEE Cat No. 04EX821), Arlington, VA, USA 1: 141-144.

Liu, Z. 2018. What is the future of solar energy? Economic and policy barriers. Energy Sources Part B-Economics Planning and Policy 13(3): 169-172.

Liu, J.J. 2017. Fast enhancement simulation of fuzzy region of low-dimensional image in fog environment. Computer Simulation 34(2): 397-400.

Liu, J., Ni, B. \& Hao, J.B. 2017. Minimum energy constrained image interaction estimation deblurring algorithm. Computer Engineering and Design 42(12): 3402-3407.

Lu, R., Song, X.X., Li, Q. \& Wang, Z. 2017. Face image processing based on fuzzy algorithm. Shandong Industrial Technology 12(13): 261-261. 
Meylan, L. \& Susstrunk, S. 2006. High dynamic range image rendering with a retinex-based adaptive filter. IEEE Trans. Image Processing 15(9): 2820-2830.

Pal, S.K. \& King, R. 1981. Image enhancement using smoothing with fuzzy sets. IEEE Trans. Systems, Man, and Cybernetics 11(7): 494-500.

Prabha, D.S. \& Kumar, J.S. 2017 An efficient image contrast enhancement algorithm using genetic algorithm and fuzzy intensification operator. Wireless Personal Communications 93(1): 223-244.

Quan, Y.Q., Li, T.J., Deng, J.X. \& Xie, K.M. 2016. Adaptive image enhancement algorithm based on fuzzy set and nonlinear gain. Computer Application Research 1: 311-315.

Ramos Gandolfi, O.R., Goncalves, F.G.R., Bonomo, F.R.C. \& Fontan, I.R.D.C. 2018. Sorption equilibrium and kinetics of thin-layer drying of green bell peppers. Emirates Journal of Food and Agriculture 30(2): 137-143.

Ren, K.Q., Hu, M.Y. \& Yu, L.J. 2017. Adaptive fuzzy image registration algorithm based on kaze. Journal of Electronic Measurement and Instrumentation 31(4): 559-565.

Sanchez Camacho, E.A. \& Martinez Morales, M. 2017. Estimation of the volume of underground water for a coastal wetland. Revista Internacional De Contaminacion Ambiental 33(SI): 65-76.

Shakeri, M., Dezfoulian, M.H., Khotanlou, H., Barati, A.H. \& Masoumi, Y. 2017. Image contrast enhancement using fuzzy clustering with adaptive cluster parameter and sub-histogram equalization. Digital Signal Processing 62: 224-237.

Shi, Z.G. 2007. Method of membership function based on fuzzy theory by pso algorithm optimized. Computer Engineering \& Applications 43(18): 84-86.

Song, R., Da, L.I. \& Wang, X. 2017. Low illumination image enhancement algorithm based on HSI color space. Journal of Graphics 38(2): 217-223.

Sun, W., Dong, E. \& Qiao, H. 2017. A fuzzy energy-based active contour model with adaptive contrast constraint for local segmentation. Signal Image \& Video Processing 12(12): 1-8.

Wang, B.P., Ma, J.J., Han, Z.X., Zhang, Y., Fang, Y. \& Ge, Y.M. 2018. Adaptive image enhancement algorithm based on fuzzy entropy and human visual characteristics. Systems Engineering and Electronic Technology 29(5): 1079-1088.

Wang, F.P., Wang, W.X., Yang, N. \& Sui, L.C. 2017. Urban traffic image enhancement based on improved retinex. Journal of Transportation Systems Engineering and Information Technology 2017(5): 53-59.

Wang, H. \& Zheng, B.G. 2016. Image reconstruction algorithm based on weighted TV/sar joint prior and minimum linear KL divergence. Measurement and Control Technology 35(1): 38-42.
Wang, K. 2017. Research of enhancement algorithm for infrared image based on the fuzzy set theory. IOP Conference Series Earth and Environmental Science 69(1): 012180.

Yi, S.L., Chen, Y. \& He, J.F. 2016. Fourth - Order equation image smoothing method for establishing a novel edge leakage compensation mechanism. Acta Electronica Sinica 44(4): 813-820.

Yue, G.W., Lu, X.S., Liu, B. \& Liu, R.F. 2016. Wellbore disease identification method based on improved active contour model. Coal Engineering 48(5): 115-118.

Zadeh, L.A. 1965. Fuzzy Sets. Inform. Control 8: 338-353.

Zhang, X., Zhao, X.F., Shi, Y.L. \& Zhao, S.F. 2017. Adaptive merge histogram stretch enhancement algorithm for UUV sea surface infrared reconnaissance image. Applied Science and Technology 43(6): 1-4.

Zhou, F., Jia, Z.H., Yang, J. \& Kasabov, N. 2017. Method of improved fuzzy contrast combined adaptive threshold in NSCT for medical image enhancement. BioMed Research International 10: 3969152.

Zong, H., Cao, Y. \& Liu, Z. 2018. Energy security in group of seven (g7): A quantitative approach for renewable energy policy. Energy Sources Part B-Economics Planning and Policy 13(3): 173-175.

Xi Chu, Zhixiang Zhou* \& Xiaoju Xiang

School of Civil Engineering \&

Department of State Key Laboratory Breeding

Base of Mountain Bridge Tunnel Engineering

Chongqing Jiaotong University

Chongqing, 400074

China

Chaoshan Yang

Department of Military Installations

Department of Army Logistics University of PLA

Chongqing, 401331

China

*Corresponding author; email: jfnchuxi@yahoo.com

Received: 21 February 2019

Accepted: 23 December 2019 